\title{
REVISTAMARACANAN
}

\section{As vidas abertas da América Latina: escritas (auto)biográficas}

\author{
The open lives of Latin America: (auto)biographical writings \\ Las vidas abiertas de América Latina: escritos (auto)biográficos
}

\begin{abstract}
Wilton C. L. Silva*
Universidade Estadual Paulista - Campus de Assis,

Brasil

Aurelia Valero Pie ${ }^{* *}$

Universidad Nacional Autónoma de México, México
\end{abstract}

Em uma época marcada pelo retorno ao sujeito - seja à maneira do que Paula Sibila denominou "intimidade como espetáculo", seja no contexto de um crescente interesse acadêmico pelas trajetórias da vida e pelos meandros da subjetividade - não resulta de coincidência que nas

A coordenação deste dossiê foi realizada como parte do projeto PAPIIT IA400919 "La biografía en México: identidad, historia y escritura", com recursos do Programa de Apoyo a Proyectos de Investigación e Innovación Tecnológica da Universidad Nacional Autónoma de México.

* Professsor Associado do Departamento de História da Universidade Estadual Paulista - UNESP, Campus de Assis. Livre-Docente em Metodologia da Pesquisa Histórica e Doutor em História pela UNESP-Assis; Mestre em Sociologia e graduado em Ciências Sociais pela Universidade Estadual de Campinas. (wilton.silva@unesp.br)

CV Lattes: http://lattes.cnpq.br/7506207238645739

ORCID iD: https://orcid.org/0000-0002-1507-8017

** Pesquisadora e Professora da Unidad de Investigación sobre Representaciones Culturales y Sociales, Universidad Nacional Autónoma de México. Doutora em Historia por El Colegio de México; Mestre em Filosofía pela École Normale Supérieure e pela Université Paris IV - Paris-Sorbonne; Graduada em Filosofia pela Université Paris I - Panthéon-Sorbonne. (aureliavalero@gmail.com)

ORCID iD: https://orcid.org/0000-0002-4759-9124 
últimas décadas as explorações em torno do "eu" tenham se multiplicado e diversificado, assim como as expressões de tipo (auto)biográfico. Biografias, autobiografias, memórias, testemunhos, histórias de vida, diários íntimos, correspondências, cadernos de notas, de viagens, rascunhos, lembranças de infância, autoficções, romances, filmes, vídeo e teatro autobiográficos, além da chamada reality painting, os inúmeros registros biográficos das entrevistas midiáticas, conversas, retratos, perfis, anedotários, indiscrições, confissões próprias e alheias, velhas e novas variantes do show (talk show, reality show), a vídeo-política, os relatos de vida das ciências sociais e, ainda, as novas ênfases da pesquisa e da escrita acadêmica, são apenas algumas formas dessa manifestação que a crítica literária argentina Leonor Arfuch identifica como "espaço biográfico".

A partir desse leque de manifestações, há urgência em se pensar o sujeito e suas múltiplas relações com distintos grupos, sua cultura e seu tempo, seu legado e sua memória, sendo que o presente dossiê, que tivemos o prazer de organizar para a Revista Maracanan, busca apresentar alguns exemplos de tais possibilidades a partir de uma perspectiva multidisciplinar e que abarque distintas realidades latino-americanas. Tal iniciativa visa avançar em uma tarefa necessária, a saber, convidar a refletir sobre o "espaço biográfico" a partir das referências teóricas, tradições intelectuais e particularidades históricas de nossa região, o que justifica o título escolhido: "As Vidas Abertas da América Latina".

Os resultados aqui apresentados, a partir de um esforço coletivo, foram quinze trabalhos, entre artigos, depoimento, relatos de experiências de pesquisa e resenhas, de dezenove autores de diferentes países e com diferentes formações, e que a partir de objetos, fontes e metodologias distintas se inserem na abordagem do estudo e reflexão sobre a escrita biográfica e autobiográfica, contribuindo para um panorama de parte do que se tem estudado sobre o tema nos anos recentes.

Em contraste com as análises convencionais sobre biografia, em seu desenvolvimento histórico, Rodrigo Terrazas se compromete no artigo que abre este dossiê com um primeiro esforço para identificar os eixos que articulam a reflexão no México sobre o gênero. A partir de um estudo de caso da produção biográfica mexicana na transição do século XX para o XXI, discute de que maneira a historiografia local tem enfrentado as questões e os desafios colocados por esse tipo de narrativa. Ancorando-se no contexto local, Terrazas descobre que a recuperação do gênero biográfico nos últimos anos responde, em parte, ao reconhecimento e à discussão de sua dimensão literária, bem como a um progressivo interesse por parte da academia.

Uma prova do papel da literatura em novos desenvolvimentos na biografia aparece nos respectivos artigos de Julia Musitano e Patricio Miguel Fontana.

Em "La realidad tiene el tamaño de la imaginación", Musitano problematiza a relação entre verdade e ficção na biografia a partir de El bastardo (1997), biografia do poeta e diplomata uruguaio Roberto de las Carreras, escrita por Carlos Maria Dominguez. Esta obra narra a conturbada vida de um bastardo de rica família que obteve reconhecimento intelectual, ocupou 
importantes posições e terminou a vida enlouquecido, e cuja narrativa se equilibra entre aquilo que os documentos e depoimentos afirmam e o que o autor se permite criar. Essa ambiguidade é o que permite a autora aprofundar as distinções entre a "biografia literária" e a "biografia novelada", em uma abordagem sugestiva que expõe o alcance e as limitações de tais modelos narrativos.

O problema sobre as formas das classificações também ocupa Patricio Fontana em "Tener mi vida organizada por otros", terceiro artigo deste dossiê, no qual a análise aborda a leitura enquanto biografia de Magnetizado (2018), elogiado livro do argentino Carlos Busqued, identificado como uma ousada e perturbadora experiência literária e estética na qual se apresenta a reconstrução da vida de Ricardo Melogno, que cumpre pena em uma instituição psiquiátrica por sua condenação pela morte, sem motivos aparentes, de quatro taxistas em Buenos Aires, na Argentina, no ano de 1982. Construída em torno de diálogos, a narrativa escapa às definições atuais que delimitam o romance, o testemunho e a biografia, ao mesmo tempo em que obscurece as fronteiras entre o que diz o biografado e o que escreve o biógrafo.

Passamos então aos artigos que lidam com a autobiografia, um gênero que transita entre verdade e ficção, história e memória, contexto e experiência. Como sintoma de um conflituoso século $X X$, marcado pela violência e migração forçada, dois deles apresentam os casos de autores deslocados de sua língua e cultura nativas, escritores que desenvolveram seu trabalho sob a marca do trauma.

O primeiro texto em português do dossiê, "Poética da escavação", apresenta fragmentos das memórias da poetisa e tradutora de origem argentina Laura Alcoba. Sua obra poética é analisada por Dayane Moura \& Silvina Carrizo enquanto vestígio do exílio na infância de uma filha de militantes do grupo Montoneros que acompanhou os pais para a França, onde foi criada, se fixou e passou a escrever na língua local.

O segundo texto referido é "Memoria individual y colectiva en Viena: una ficción de Andreas Kurz", de Mario Cesar Islas Flores. O discurso ensaístico de Kurz Essmeister, crítico literário e ensaísta de origem austríaca radicado no México, tal como aparece nesta obra, permite a Islas Flores propor uma profunda reflexão sobre o testemunho e suas múltiplas dimensões, problematizando as dimensões ficcionais, o esquecimento e as distorções voluntarias e involuntárias da memória. Paradoxalmente, é o recurso à literatura que permitiria reinserir a experiência vivencial na história.

Um procedimento inverso é encontrado no sexto artigo, "A crença no Profeta", de Mariana Dias Antonio \& Marcella Lopes Guimarães, uma abordagem crítica, confrontando o relato pessoal com outras fontes, nas memórias do mitológico empresário e jornalista russo-brasileiro Samuel Wainer, apresentadas em sua autobiografia Minha Razão de Viver (1980) e que é referência recorrente em estudos acadêmicos sobre a imprensa no Brasil do século XX. Através de uma análise minuciosa, em que apresentam os processos de elaboração e edição de tal 
autobiografia, as autoras não só desmitificam passagens do relato como ainda mostram a autobiografia como um gênero híbrido, no qual se cruzam a mimeses e a vida imaginada.

Em "A perspectiva interseccional-rizomática nas narrativas (auto)biográficas de universitárias", Andrea Abreu Astigarraga descreve e analisa as memórias autobiográficas de estudantes universitárias enquanto relatos de vida e formação, assinalando a presença e forma de manifestação de marcadores discursivos de etnia, classe e gênero das narradoras, o que permite avaliar os processos de mobilidade social, bem como seus efeitos na construção de si pelos entrevistados.

Finalmente, em "Narrativas Locais e Memória Coletiva", Gerlane Bezerra Rodrigues \& Juliana Rodrigues Morais, discutem a partir de três diferentes monumentos da cidade de Vitória da Conquista, que homenageiam os Bandeirantes, Nossa Senhora da Vitória e os índios Mongoiós, a valorização pelo poder local, a partir da década de 1980, das memórias de setores antes excluídos das narrativas identitárias presentes naquele município e em sua região. " $\mathrm{A}$ resistência - afirmam as autoras - toma a forma de fragmentos do passado que se tornam memórias coletivas".

Na seção Depoimentos, temos o prazer de apresentar o texto "Biografar a Beatriz Sarlo", de Judith Gabriela Podlubne, que oferece uma rica reflexão sobre o desafio da escrita biográfica partindo de sua experiência pessoal na tentativa de analisar e compreender memórias da crítica literária argentina. A infância de Sarlo, considerada como secundária nos primeiros momentos da pesquisa, revela-se como um elemento central ao se examinarem os relatos que a autora faz em La máquina cultural (1998), utilizando-se das referências de Rosa Del Rio, sua tia, para entremear o vivido, o lembrado e o narrado, desta forma mapeando-se o caminho de ida e de volta entre a vivência e a escrita.

A seção de Notas de Pesquisa, por sua vez, é iniciada com "De la anécdota a la biografia", relato de Mario Alberto Magaña Mancillas sobre sua experiência em um projeto de História Oral envolvendo moradores das zonas rurais de Ensenada, Baja Califórnia, no México, e das publicações que resultaram da pesquisa: um livro de causos e anedotas, um sobre memórias de cinco mulheres indígenas, outro de testemunho autobiográfico e, ainda, uma biografia.

Também a história oral, ou, o que os autores identificam como histórias de vida constituem o eixo do texto seguinte, de Veronica Pacheco de Oliveira Azeredo \& Marília Sousa Andrade Dias, com o título "Alicia Vega", uma avaliação da teoria pedagógica da intelectual chilena sobre a sensibilização de crianças pobres para o cinema através de suas pioneiras oficinas que uniam estética, ensino e impacto social, resgatando relatos orais de pessoas que se envolveram de diferentes formas com tal projeto.

Para encerrar a seção, temos "Assim foi meu passado", de Geovanni Gomes Cabral, que expõe o processo de escrita da autobiografia versificada do cordelista paraibano, radicado em Pernambuco, José Costa Leite. Intitulada $A$ vida da minha vida (2013) e escrita em meio a 
produção de cordéis, xilogravuras e almanaques populares de um representante da cultura popular nordestina, nesta obra se conjugam lembranças, formas de auto-representação e diferentes temporalidades.

O dossiê se encerra com três resenhas: a primeira a respeito de coletânea sobre o tema da biografia publicada na Argentina; a segunda enfoca obra sobre a trajetória política do crítico de arte e militante comunista Mário Pedrosa (1900-1981); e, por último, uma sobre biografia de Octavio Augusto da Cunha Corrêa, o único civil morto no episódio tenentista conhecido como a Revolta dos 18 do Forte de Copacabana, no Rio de Janeiro, em julho de 1922.

A resenha de João Muniz Júnior, intitulada "Os caminhos da biografia", descreve uma coletânea, organizada por Nora Avaro, Julia Musitano e Judith Podlubne, com o título Un arte vulnerable: la biografia como forma (2018), em que são apresentados capítulos sobre teorias, métodos, experiências e possibilidades sobre e da escrita biográfica e autobiográfica.

Victor Emmanuel Farias Gomes avalia a biografia política escrita por Dainis Karepovs, com o título Pas de Politique Mariô!: Mário Pedrosa e a política (2017), uma narrativa que dimensiona as opções intelectuais e políticas do intelectual e militante de esquerda Mario Pedrosa entre 1920, ano de sua filiação ao Partido Comunista do Brasil (PCB), e 1980, ano de uma nova filiação ao nascente Partido dos Trabalhadores e de sua morte.

E, encerrando o dossiê, a explanação de Lucas Mateus Vieira de Godoy Stringuetti sobre a biografia escrita por Afonso Licks sobre Octavio Augusto da Cunha Corrêa, com o título Octavio, o civil entre os 18 do Forte de Copacabana (2016), o que é entendido como um resgate de um personagem que foi, de certa forma, esquecido ao longo do tempo.

Assim, se por um lado, todas as muitas maneiras em que se manifesta o espaço biográfico não estão contempladas nos textos que o presente dossiê nos traz; por outro, com certeza, tratase de um panorama amplo e plural de formas de se pensar o biográfico e o autobiográfico em algumas regiões da América Latina, construído com a valiosa contribuição de pesquisadores de diferentes áreas do conhecimento, e que se afirma como um convite para a reflexão sobre um tema privilegiado.

Desfilam como pano de fundo dos trabalhos aqui apresentados discussões teóricometodológicas, problemas de linguagem, dramas e traumas do exílio e da exclusão, as implicações do crime e da loucura, as relações entre fato e ficção, a riqueza das histórias de vida, as complementariedades entre prosa e poesia, discussão sobre patrimônio e memória, os desafios da história oral, o papel do ensino e a necessidade da inclusão social, entre outros temas.

Entendemos que é um resultado feliz e honroso e esperamos que os leitores desfrutem de forma enriquecedora da leitura. 